\title{
Farm level risk factors for fluoroquinolone resistance in $E$. coli and thermophilic Campylobacter spp. on finisher pig farms
}

\author{
N. M. TAYLOR ${ }^{1 *}$, F. A. CLIFTON-HADLEY ${ }^{2}$, A. D. WALES ${ }^{2}$, A. RIDLEY $^{2}$ AND R. H.
} DAVIES $^{2}$

\footnotetext{
${ }^{I}$ Veterinary Epidemiology and Economics Research Unit, School of Agriculture, Policy and Development, University of Reading, Earley Gate, P.O. Box 237, Reading, Berkshire RG6 6AR, UK.

${ }^{2}$ Veterinary Laboratories Agency - Weybridge, Department of Food and Environmental Safety, New Haw, Addlestone, Surrey KT15 3NB, UK.
}

* Author for correspondence and reprints: Mr Nick M. Taylor, Veterinary Epidemiology and Economics Research Unit, School of Agriculture, Policy and Development, University of Reading, Earley Gate, P.O. Box 237, Reading, Berkshire RG6 6AR, UK. n.m.taylor@ reading.ac.uk

Running head: Fluoroquinolone resistance on finisher pig farms 


\section{SUMMARY}

Logistic regression, supported by other statistical analyses was used to explore the possible association of risk factors with the fluoroquinolone (FQ)-resistance status of 108 pig finisher farms in Great Britain. The farms were classified as 'affected' or 'not affected' by FQ-resistant E. coli or Campylobacter spp. on the basis of isolation of organisms from faecal samples on media containing $1 \mathrm{mg} . \mathrm{l}^{-1} \mathrm{FQ}$. The use of FQ was the most important factor associated with finding resistant $E$. coli and/or Campylobacter, which were found on 79\% (FQ-resistant E. coli) and 86\% (FQ-resistant Campylobacter) of farms with a history of FQ use. However, resistant bacteria were also found on 19\% (FQ-resistant E. coli) and 54\% (FQ-resistant Campylobacter) of farms with no history of FQ use. For FQ-resistant E. coli, biosecurity measures may be protective and there was strong seasonal variation, with more farms found affected when sampled in the summer. For FQ-resistant Campylobacter, the buying in of grower stock may increase risk and good on-farm hygiene may be protective. The findings suggest that resistant organisms, particularly Campylobacter, may spread between pig farms. 


\section{INTRODUCTION}

The issue of antimicrobial resistance among bacteria of veterinary origin has been a significant concern in respect of both human and animal health for many years [1]. Since the approval of fluoroquinolone (FQ) antibiotics for animal use in the 1990s, there has been evidence that FQ resistance of veterinary origin is appearing in human patients, particularly in cases of salmonellosis and campylobacteriosis [2,3]. The issue of FQ resistance and its links to veterinary sources prompted a farm-level study of FQ resistance in thermophilic Campylobacter spp. and E. coli, of which the present report is a part.

The reported prevalence of Campylobacter excretion amongst slaughter-weight pigs is around $60 \%$ to $100 \%$ [4-6]. In neonatal piglets, diarrhoea may be seen in association with exposure to Campylobacter coli or Campylobacter jejuni [7], but colonisation by Campylobacter is generally asymptomatic. In most surveys, $C$. coli is the heavily predominant species amongst pigs [5, 8-10], although $C$. jejuni predominates in some American studies $[4,11]$. Typing studies suggest that pigs are relatively less important as a source of zoonotic $C$. coli when compared with other food animals, particularly poultry [6,12-14]. This may be due to post-slaughter treatment of pig carcases that is unfavourable to survival of Campylobacter. Rapid selection of resistance has been observed in FQtreated pigs: $C$. coli readily acquires a clinically-relevant level of resistance to FQ [15], and generally exhibits a higher level of resistance to antimicrobials than does $C$. jejuni $[6,16,17]$. FQ resistance may be found on pig units that do not use these antimicrobials [10], and studies of conventional slaughter-weight pigs in France have yielded FQ-resistant Campylobacter sp. at prevalences of between $11 \%$ and $24 \%$ of isolates $[8,18]$. Concerns have been expressed about the ecological problem of environmental contamination with such resistant organisms in animal waste $[8,18]$.

E. coli is universally present in the intestines of pigs, and most strains are commensals which are not associated with disease [19]. However, some E. coli strains which possess certain adhesion, invasion and /or toxigenic capabilities are considered to be primary porcine pathogens, capable of causing enteritis, septicaemia or oedema disease [7]. Resistance to FQ amongst E. coli is commonly seen in human and veterinary isolates $[20,21]$, and there is evidence of the transfer of antimicrobialresistant porcine E. coli to human intestinal flora [22].

The current study involved cross-sectional sampling of finisher pig and poultry meat production units for FQ resistance, focusing on Campylobacter and E. coli, to assess the level of FQ resistance in these sectors in the UK [23]. The prevalence of FQ resistance was examined at the farm level. Simultaneously, data were collected to provide the basis for an exploratory risk factor analysis. The present report describes the results of this analysis for finisher pig farms. The risk factor analysis for poultry farms will be reported elsewhere. 


\section{MATERIALS AND METHODS}

\section{Data collection}

Data were taken from farms participating in a survey to estimate farm level prevalence of FQresistance [23]. The target population was defined as: "pig finishing (breeding to finishing, or growing and finishing) farms in Great Britain, with at least 100 breeding females if breeder to finish, or 200 finisher places if specialist finishers". There were 2,650 eligible holdings according to the June 2002 Agricultural Census. A desired sample size of 330 farms had been calculated on the basis of attaining an estimate of proportion of farms 'affected' with a 95\% confidence interval (C.I.) of $\pm 5 \%$. However, the final sample size obtained was affected by industry apprehension and willingness to take part. Four hundred and sixteen pig farms, selected at random from lists provided by Quality Meat Scotland (QMS), Assured British Pigs and the National Pig Association, were contacted by their organisations and invited to join the study. Partly due to the sensitive nature of the study, only 108 farms agreed to take part. This population of sampled farms matched the geographical distribution of the national herd. The sample contained both breeder/finisher and non-breeding grower/finisher farms. Breeding farms made up 55\% of the sample, compared with 59\% of eligible British holdings which had breeding pigs in the June 2002 Agricultural Census.

Data about husbandry practices, performance criteria, disease and drug use were collected using detailed questionnaires completed by the farm manager and the farm's private veterinarian who was contracted to do the sampling. Information about recent usage of FQ and other prescription drugs on the farm was verified by the farm's private veterinarian using farm and practice records.

\section{Categorisation of farms for FQ- resistance}

The 108 participating pig farms were classified as 'affected' or 'not affected' with respect to FQresistance among E. coli and thermophilic Campylobacter spp. following bacteriological analysis of faeces samples taken as part of a cross-sectional survey carried out between December 2002 and October 2003, the details of which are reported elsewhere [23]. The sampling protocol was devised to provide a $95 \%$ confidence level for detecting affected farms assuming a minimum prevalence of $5 \%$ of animals shedding resistant bacteria and a $90 \%$ sensitivity of laboratory detection.

Briefly, measured aliquots of 8 pools of $\geq 8$ fresh faeces samples from finishing pigs were cultured on semi selective media (Chromagar ECC, CM956, Oxoid for E. coli and BASAC [24] for thermophilic Campylobacter) containing $1 \mathrm{mg} \mathrm{l}^{-1}$ ciprofloxacin before and after broth enrichment. The identities of putative E. coli and Campylobacter colonies were confirmed using standard biochemical tests. The growth of colonies typical of E. coli or Campylobacter spp. on ciprofloxacincontaining media was taken to indicate that FQ-resistant bacteria were present in the faeces and therefore the farm of origin was classed as 'affected'. Minimum inhibitory concentrations of ciprofloxacin for the FQ-resistant bacteria were estimated based on an agar doubling dilution methodology $[25,26]$ and all were shown to be $\geq 2 \mathrm{mg} \mathrm{l}^{-1}$ with $90 \% \geq 8 \mathrm{mg} \mathrm{l}^{-1}$. To demonstrate the presence or absence of Campylobacter on the farm in the case of no growth on ciprofloxacincontaining media, swabs from pooled faeces samples were also plated on ciprofloxacin-free BASAC after enrichment in Exeter broth.

\section{Statistical analysis}

The questionnaire generated a huge number of variables. In an initial exploration of the data, univariate analyses were carried out for potential risk factors with respect to odds of occurrence of FQ-resistant E. coli and FQ-resistant Campylobacter. These analyses were done using exact conditional logistic regression, using the exact statement of SAS proc logistic in SAS version 8.2 [27] in order to provide exact $95 \%$ confidence intervals. Following the recommendation of Agresti [28] inference based on the mid-p value was used to alleviate conservativeness in the exact confidence intervals.

As a preliminary to the final regression analyses, variables were further rationalised using correlation and cluster analyses, also in SAS [27]. The questionnaire data were first broken up into 
blocks according to subject matter (e.g. farm characteristics, farm hygiene, biosecurity, drug usage). The analytical process then looked at each block in turn, before combining data from all blocks in a final analysis. The approach taken was as follows:

Step 1. Each block of data contained variables that could be expected to be related: for example, the provision and use of site-dedicated boots on farms and the use of site-dedicated overalls, or the provision of a toilet for staff and the provision of a washbasin. In a regression model the inclusion of one of a group of related variables would 'stand for' all variables in that group. Screening among variables within each block was performed to identify groups of related variables. Using $1-r^{2}$ as a distance measure between all possible pairs of variables within a block (where $r=$ the Spearman's correlation coefficient [29]), Ward's minimum variance cluster analysis $[30,31]$ was carried out to generate graphic representations of variable grouping in the form of dendrograms.

Step 2. The groups identified in Step 1 were examined in order to assess which variables should represent each group and be put forward as possible explanatory variables (risk factors) in the multiple regression. Decisions were based on epidemiological grounds, but also took into account the variability of the candidate factor in the population and data completeness (variables with more variability and more data points were favoured). The aim was to include at least one variable from each group of related variables in the regression, so that every group would be represented in the analysis.

Step 3 The key variables identified in Step 2 were tried as explanatory (independent) variables in logistic regression modelling [27] within each block, using the farm result for FQ-resistant $E$. coli (affected or not affected) or, similarly, FQ-resistant Campylobacter as the outcome (dependent) variables. In order to extract the most value from the data, despite the smaller than ideal sample size, an exploratory approach using a non-automatic variable selection procedure, as recommended by Collet [32] was used. Briefly, both forwards and backwards manual stepwise modelling was performed and the sets of variables that made the best epidemiological sense were chosen as the basis for final modelling. At the next stage, models were fitted using the maximum data available and variables originally dropped by the stepwise procedures were manually added to the base models one by one. This process often resulted in further variables being found to be significant within the model. The manual fitting process was repeated until no further variables could be added or dropped based on their statistical significance and scientific relevance. Following the recommendation of Collet [32], the criteria for significance, on which variables were included in the models, were $p \leq$ 0.1 to enter and $p>0.1$ to exit. This process identified a small number of 'candidate' risk factor variables from each block.

Step 4. Variables from different blocks could be related: for example, presence of sows, buying in of gilts and buying in of growers (block F) are all connected with the type of farm (breeding to finish or finish only - block B). Therefore, as with variables within subject matter blocks, all 'candidate' risk factor variables identified in Step 3 were screened for correlations and clustering regardless of their originating data blocks, using the statistical procedures of Step 1. Variables were omitted from the next step if there were strong correlations with other variables. For example the 'import of growers' variable was used to stand for farm type, including presence or absence of sows.

Step 5. The retained 'candidate' variables from all blocks were tried together in logistic regression modelling. The modelling procedures and criteria for significance were as described for Step 3. Having fitted main effects, interactions were checked for but inclusion of these in the regression models always resulted in estimates for some odds ratios approaching infinity or zero. This was considered to be the result of small sample sizes, such that inclusion of too many effects, notably the interactions, produced models that were 'over-fitted', as described 
by Collet [32]. To avoid the possibility of over-fitting and implausible interpretations, models were finalised without interactions.

The analysis resulted in identification of a 'final' list of risk factors for occurrence of FQ resistance in each bacterial species, and quantified the effects of these risk factors in terms of adjusted odds ratios.

The results of the final regression modelling are presented as tables showing the variables included as risk factors, estimates of coefficients with p-values, and the estimated adjusted odds ratios with $95 \%$ confidence intervals. The confidence intervals for the odds ratios were calculated using the exact statement in logistic regression [27] to adjust for the problem of small sample sizes in the strata. As in the univariate analyses, inference based on the mid-p value was used to alleviate conservativeness in the exact confidence intervals.

An $r^{2}$ value, which estimates the proportion of variation in the data explained by the model, was calculated for each model, according to the method of Nagelkerke [33] as recommended by Collet [32]. 


\section{RESULTS}

Of the 416 farms invited to take part in the survey, 345 responded. Of these, 78 were ineligible for the survey (either had stopped keeping pigs or had too few pigs). Of the remaining 267, 159 declined to take part: 34 gave reasons related to lack of time and money; 24 gave a variety of other reasons and 101 gave no reason. Thus 108 farms took part in the survey.

FQ-resistant E. coli were isolated from 63/108 farms. FQ-resistant Campylobacter were isolated from 81/108 farms; no Campylobacter were detected on 20/108 farms and Campylobacter were isolated from a further 7/108 farms on which no FQ-resistant Campylobacter had been isolated.

\section{Use of FQ antibiotics and risk of resistance on the surveyed farms}

In relation to the use of FQ on farms, the questionnaire response options were: 'within 12 months'; 'between one and two years ago'; 'over two years ago'; and 'never'. Table 1 shows the breakdown of responses. Use of FQ was reported on 71 (66\%) of 108 farms in the survey. Almost half of all farms had used FQ in the last year and more detail about the usage was available for these farms. The most common conditions treated with FQ were reported to be 'enteric problems' or 'scouring'. The most common formulation recently employed was 5 or $10 \%$ injectable solution, used on 50 of the 53 farms that had used FQ within the last year. An oral FQ piglet doser had been used on 12 farms, three of which had not additionally used an injectable form. FQ had been used in all classes of pig, but use was most commonly reported in piglets, in 36 of the 53 farms.

FQ-resistant E. coli and/or Campylobacter spp. were detected on $96 \%$ of the farms that had a reported history of FQ use. The proportions of farms affected by FQ-resistant E. coli and Campylobacter were lower among farms where the most recent use of FQ had been over one year ago than among those using FQ within the last year (Table 1). However, these differences were not statistically significant (Fisher's two-tailed exact test: E. coli, $\mathrm{p}=0.1837$; Campylobacter, $\mathrm{p}=$ 0.4339). For this reason, in further analyses, farms where any FQ use had been reported were grouped together as having used FQ within the recent past, for comparison with those farms reporting that they had never used FQ.

\section{Modelling of risk factors for the occurrence of FQ-resistance on finisher pig farms}

Tables 2 and 3 list the variables that were selected from the questionnaire data for analysis. Univariate odds ratios for the association between each variable and farm status with respect to resistance are shown, with exact mid-p confidence intervals. The numbers of farms exposed or not exposed to each putative risk factor and positive for resistance $(\mathrm{R}+)$ or negative for resistance (R-) are shown. Data sparsity is indicated in Tables 2 and 3 by using bold italic wherever the number of farms in any one exposed/resistant category is five or less.

Correlation and clustering analysis revealed that several of the variables were highly correlated with each other. Specifically:

- The existence of sows on the farm (breeding farm) was positively correlated with unloading pigs at the perimeter, the requirement for visitors to be free of pig contact for at least two days, the buying in of gilts and the recognition of a rodent problem; it was negatively correlated with the importation of growers and weaners;

- The buying in of growers was negatively correlated with the unloading of pigs at the perimeter of the farm.

- The existence of a pig farm within 1 mile was positively correlated with the existence of a poultry farm within 1 mile.

- In this particular sample of pig farms, the variable 'provision of a boot brush' was connected with several other, seemingly unrelated, hygiene and biosecurity variables; it was negatively correlated with requirement for visitors to be free of pig contact for at least 2 days, provision of wash basin, toilet and soap and provision of boots and overalls for visitors.

Table 4 provides a summary of the factors included in the final fitted logistic regression model for the risk of occurrence of FQ-resistant $E$. coli. Three variables are included with p-values between 
0.07 and 0.1 . The only model in which all variables have $p$-values $<=0.05$ is a model containing only the variables related to use of fluoroquinolone and season. Inclusion of the three further variables in the model does not greatly change the p-values or the estimated odds ratios of these two factors and provides more complete epidemiological information. Factors associated with increased risk are: the use of FQ in the recent past, the existence of another pig farm within one mile of the site, and sampling carried out in the spring and especially summer seasons in comparison with autumn and winter. Factors associated with decreased risk are: the existence of a poultry farm within one mile of the site and the requirement for farm visitors to be free from pig contact for at least two days. The $r^{2}$ value is over $50 \%$, indicating that the model provides a good explanation of factors affecting the occurrence of FQ-resistant E. coli.

Table 5 provides an equivalent summary for FQ-resistant Campylobacter. Three of the variables were included with p-values between 0.06 and 0.07 . However, all of these variables had $\mathrm{p}<=0.05$ when one of the others was dropped from the model. Two candidate models were found with all variables having $\mathrm{p}<=0.05$, but no justification could be found for choosing one of these models above the other. A more informative epidemiological impression is therefore given by presenting the model containing all these variables. Factors associated with increased risk are: the use of FQ in recent past, the buying-in of growers and the provision of boot brushes outside buildings. Factors associated with decreased risk are: a requirement for farm visitors to be free from pig contact for at least two days and a top housekeeping score given by the veterinary surgeon filling in the questionnaire. This last factor contained a 'bundle' of details related to maintenance, cleaning and biosecurity on the farm and is interpreted as an indicator of generally superior management of the farm. It is also important to remember that provision of a boot brush was associated, in this sample of farms, with lack of provision of wash basin, toilet and soap for staff and boots and overalls for visitors. The $\mathrm{r}^{2}$ value is just below $50 \%$, indicating that the model provides a reasonable explanation of factors affecting the occurrence of FQ-resistant Campylobacter. However, there could be other important unidentified factors. 


\section{DISCUSSION}

The present survey and risk factor analysis was designed to identify factors that increase or decrease the risk of FQ resistance occurring on farms. The farm sample size obtained was restricted by farmers' willingness to take part. The fact that only $26 \%$ of farms originally contacted took part could be a source of selection bias in the sample. The British pig industry was undergoing a significant contraction during the period of the study and many farmers were leaving the industry. Seventy-eight farmers out of 159 who gave detailed reasons for not taking part ruled themselves out for the reason that they no longer kept pigs, or kept too few. It cannot be known how many of the 172 farmers who gave no reason for not wishing to participate, or who did not respond at all, might also have recently stopped keeping pigs, but there could have been a high number in this group.

The study described here was just one of three being carried out concurrently in the same sample of farms, so farmers did not necessarily decline from the study for reasons that could be related to the use of FQ antimicrobials. Indeed, within the sample, the proportion of farms reporting FQ use does not appear unusually low. The population of sampled farms matched the geographical distribution of the national herd and the sample contained proportions of breeder/finisher and nonbreeding grower/finisher farms close to that revealed in the June 2002 Agricultural Census. The survey has provided a snapshot of biosecurity, hygiene and related practices on pig finisher farms. Tables 2 and 3 summarise the proportions of farms that have particular characteristics, use a variety of husbandry practices and use a variety of drugs. The impression of the authors is that the sample of farms was not biased towards what might be called either 'good practices' or 'bad practices'. Therefore, whilst caution is advised in view of the potential for selection bias, the authors feel that the results reported here are valid as an initial indication of what might be important risk factors for occurrence of FQ-resistant organisms on pig farms.

Many of the variables on biosecurity, hygiene and associated practices were related, indicating that farmers often adopt, or do not adopt, bundles of practices as a package, or that variables are linked because of the way a farm is operated. For example, breeding farms tended to practice better boundary biosecurity control than non-breeding farms. The use of Ward's minimum variance cluster analysis proved to be a convenient way to identify groups of variables that were clustered in this way, allowing epidemiologically meaningful analysis and interpretation to be carried out. A major advantage of this approach, over carrying out pairwise association tests such as Chi-square tests, between variables, is that Ward's analysis can handle many variables at one time and produces graphical output in the form of dendrograms that identify clustered groupings of variables.

At the outset, it was anticipated that FQ-resistant E. coli or Campylobacter would be found on a small percentage of farms, that there would be farms using FQ that were not affected and there would be very few farms not using FQ that were affected. It was found that FQ-resistant E. coli and/or Campylobacter were detected on a very high proportion (96\%) of farms that had used FQ in the past. Indeed, the use of FQ was by far the most important factor influencing the occurrence of FQ-resistant bacteria on farms, having the highest odds ratios in the logistic regression models. A separate analysis showed that there were no statistically significant differences in risk between farms where the most recent use of FQ had been within the previous year and those using FQ more than one year previously. However, FQ-resistant bacteria were also detected on a substantial proportion of farms that reported having never used FQ, particularly in the case of Campylobacter.

Using the results of the current surveys alone, it is impossible to explain fully the factors influencing the occurrence of FQ resistance on non-FQ-using farms. The small sample size and data sparsity, as indicated in Tables 2 and 3, has precluded the identification of a full set of statistically significant and strongly associated risk factors and the calculated $95 \%$ confidence intervals for the odds ratio estimates in the final models (Tables 4 and 5) are wide as a result. Caution is advised in interpreting the results, which should be seen as indicating some epidemiologically plausible factors that warrant further investigation, rather than robust evidence of causal association. 
The list of variables presented in Tables 2 and 3 has been reduced from the complete set of variables extracted from the questionnaire. This reduction was made on the basis that variables within subject matter blocks can be related and act as proxies for each other. Similarly, variables in different blocks were found to be related: thus, although there are several variables in Tables 2 and 3 with statistically significant univariate odds ratios, only one or two of these were included in the final multivariate models: for example, the use of some types of antibiotic other than FQ was often associated with use of FQ, therefore these variables were not required in the multivariate model. It is also important to remember that a variable in the final model may actually be representing the epidemiological impact of several factors.

It appears from the present data that resistant organisms can be spread between farms, leading to resistance on premises where FQ have never been used. The establishment and persistence of such organisms in the absence of the selective pressure of FQ use can be explained by the observations that mutations conferring resistance to antimicrobials often confer little or no fitness cost [34], and that so-called compensatory evolution of resistant mutants can ameliorate any such cost, or even confer a fitness advantage [35]. FQ resistance in particular does not appear to confer a heavy fitness burden in Campylobacter [36]. It is logical to assume that FQ-resistant bacteria may be introduced to, and established in, farm animal populations through the buying in of animals carrying resistant bacteria or by carriage of the resistant bacteria onto the farm by fomites. The factors affecting this spread are those that would be associated with the spread of any bacterial agent. However, there are differences in the relative importance of various factors between E. coli and Campylobacter.

The results of this analysis support the conclusion that biosecurity is important for avoidance of FQ resistance in both bacterial species examined. Requiring visitors to the farm to be free of pig contact for at least two days may have had a protective effect. This emphasises the importance of hygiene barriers and is consistent with the possibility of resistant $E$. coli being brought on farm by various 'overland' fomites such as people and wild animals. E. coli are robust, may persist for months or years in the environment $[37,38]$ and be transferred by many fomites such as workers' or animals' feet and vehicle tyres. Therefore, barrier biosecurity measures such as separation from other farms and requirements for visitors are important. For $E$. coli, the existence nearby of other pig farms, which may use FQ and therefore have FQ-resistant E. coli, appeared to be associated with increased risk. Interestingly, having a poultry farm nearby was protective, the reasons for which are uncertain but it is possible that the local environment may have been seeded with avian strains of E.coli which may have had a reduced ability to colonise pigs. During the statistical modelling, the two variables related to nearby pig and poultry farms operated as a pair: the p-value for either one was very high unless the other was also included. These variables were also positively correlated, reflecting the fact that both types of farms tend to be established in similar areas of the country (predominantly in the east). That these two variables affect the risk of occurrence of FQ-resistant $E$. coli on the pig farms in opposite ways might be explained by the fact that where there are poultry farms within 1 mile of the pig farm, even though this increases the likelihood that there are also pig farms in the area, the poultry farms 'dilute' the density of nearby pig farms. It may be hypothesized that this dilution is associated with a lower exposure to exogenous porcine-adapted strains of E. coli, which would otherwise be more likely to persist in exposed pigs.

A notably high proportion (54\%) of farms that had never used FQ had FQ-resistant Campylobacter, which strongly suggests that biosecurity breaches introducing FQ-resistant Campylobacter spp., which subsequently persist for long periods, may be a common occurrence on pig farms. An important element of this may be the buying in of pre-exposed animals, i.e. growers, and the analysis suggested the buying in of growers may be an important risk factor. Growers were generally bought in by farms that did not maintain breeding sows and therefore would buy in young pigs from other farms, where they may well have been exposed to FQ. Campylobacter on pig farms generally show a diversity of strains persisting in parallel $[39,40]$, and the acquisition of Campylobacter infections as young piglets appears to be an important determinant of strain types in 
older animals, more so than any inter-animal transfer or environmental exposure among growers or adults [41, 42]. This implies that FQ-resistant strains brought in with growers will tend to persist in that group but may not readily spread to other pigs, unless uninfected young piglets are exposed to FQ-resistant strains from older animals. A requirement for visitors to have been free from pig contact for at least two days may be protective for resistance in Campylobacter, suggesting that FQ-resistant Campylobacter may be carried between farms by people and/or vehicles and can establish in new premises by this route. The low fitness cost of FQ resistance in Campylobacter implies that there will be little or no negative selective pressure on brought in resistant strains in the absence of FQ use.

FQ-resistant $E$. coli were detected on a higher proportion of farms that were sampled in summer than on farms sampled in other seasons. The increase may possibly coincide with the seasonality of enteric disease in pigs, for which FQ treatment may have been used previously in sucking or weaned pigs. If so, then FQ-resistant strains appear to decline fairly rapidly, at least initially, following the cessation of FQ use. This may simply reflect the normal strain turnover rate in pigs rather than a particular competitive advantage of non-resistant strains. In a farm-level risk analysis of $E$. coli resistance to non-FQ antimicrobials in pigs at slaughter [43], it was concluded that the routine treatment only of young piglets with antimicrobials did not affect the levels of resistance seen at slaughter, in comparison to units not using antimicrobials routinely at any stage of production. This suggests that pigs may also exhibit rapid declines in E. coli resistant to a range of antimicrobials other than FQ, following removal of the relevant selective pressure. The relative contributions to this effect of competitive disadvantage and natural strain turnover probably vary between antimicrobials. However, the situation with regard to the decline of resistance with time is likely to be more complicated than the foregoing scenario because, whilst season produced a significant difference in resistance frequency, there was no significant difference in the frequency of affected farms between those using FQ in the last year and those using them more than a year ago. Therefore, seasonal factors potentially affecting the sensitivity of detection, for example the environmental temperature, may also have played a role in the patterns observed. This would have to be confirmed by repeat studies to confirm true seasonality and a link with meteorological trends.

Farm hygiene appears to be particularly important for resistance in Campylobacter spp. The variable 'provision of a boot brush' was associated with an increased risk of detection of FQresistant Campylobacter. On the farms sampled, this variable was connected with several other, superficially unrelated, hygiene variables such as negative correlations with the provision of wash basins, toilets, soap, and of boots and overalls for visitors. These connections are not readily explained, but the result is that the 'boot brush' variable acts as an indicator for a complex combination of variables generally associated with poor hygiene facilities. It may itself also be a direct indicator of a dirty farm, where boot brushes would be needed because boots become heavily soiled. The odds ratio associated with the provision of a boot brush can therefore be seen as a measure of the effect of a package of factors, rather than of the provision of a boot brush alone. The attainment of the top 'farm housekeeping score' is also associated with a reduced risk of detection of FQ-resistant Campylobacter, and indicates generally good performance in a package of farm maintenance, hygiene and biosecurity criteria.

Schuppers et al. [9] examined herd-level risk factors for resistance to antibiotics including FQ (ciprofloxacin) among C. coli on Swiss pig farms, using a similar approach to the present study. There was more emphasis on herd health variables, including assessments by clinical examinations, but data were not sufficient to take account of previous antimicrobial use on farms. Biosecurity and 'good housekeeping' factors were found to be important in this study also. An increased risk of finding multiple antimicrobial resistance was associated with a lack of 'all-in-all-out' batch management and with some indicators of poor herd-health.

The high proportion of FQ-using farms that had detectable resistance and the strong association of resistance with the recent use of FQ would indicate that it is difficult for farms that use FQ to avoid resistance, although a very low proportion of the bacterial population may be resistant. This 
was shown in related studies where the resistant proportion of the E. coli population in faeces from pigs on seven affected pig farms ranged between $0.008 \%$ and $53 \%$ and the resistant proportion of the Campylobacter population on five affected pig farms varied from $<10 \%$ to $100 \%$ [23]. It seems that the greatest scope for avoiding the development of FQ resistance may lie with those farms that have never used FQ, but which on the present evidence appear still to be at substantial risk of acquiring such resistance. Given the above findings, it can be suggested that to avoid FQ resistance, control measures should be focussed on minimising the likelihood that fluoroquinolones will be needed by maintaining a clean and healthy farm environment; preventing entry of resistant bacteria from outside by strengthening and maintaining biosecurity measures and preventing carry-over of resistant bacteria between groups of animals by applying high standards of farm hygiene and cleaning and disinfection between batches. This is in line with guidelines produced by the UK 'Responsible Use of Medicines in Agriculture Alliance' (RUMA; http://www.ruma.org.uk), which stress that the use of antimicrobials should be seen as complementing good management, vaccination and site hygiene. Bayer Healthcare, the major manufacturer of veterinary FQ, also states in its current guidelines for the use of quinolones in veterinary medicine [44] that "strategies aimed at reducing the need for antibiotics in disease control should be encouraged". Pathogen eradication programmes plus present and projected advances in vaccinations may reduce the already limited need for FQ use.

\section{ACKNOWLEDGEMENTS}

This work was funded by the UK Veterinary Medicines Directorate and Department for Environment, Food and Rural Affairs (Defra), under project VM02101. The authors thank Mr A. Cook and Mr A. Miller for collaboration on sampling of pig farms within Defra project OZ0316; $\mathrm{Mr}$ J. Gallagher for statistical support and the veterinary surgeons, farmers and companies without whose support this project could not have been conducted.

\section{DECLARATIONS OF INTEREST}

None. 
Table 1: Detection of fluoroquinolone (FQ)-resistant bacteria on finisher pig farms in Great Britain during 2002-03, according to the timing of the most recent use of FQ

\begin{tabular}{llll} 
& & \multicolumn{2}{l}{ Number with FQ resistance } \\
\cline { 3 - 4 } $\begin{array}{l}\text { Last use of FQ } \\
\text { antibiotics }\end{array}$ & $\begin{array}{l}\text { Number } \\
\text { of farms }\end{array}$ & E. coli & Campylobacter \\
\hline In last year & 53 & $44(83 \%)$ & $47(89 \%)$ \\
Over 1 year ago & $18 *$ & $12(67 \%)$ & $14(78 \%)$ \\
Never used & 37 & $7(19 \%)$ & $20(54 \%)$ \\
\hline
\end{tabular}

* 13 of these 18 reported most recent use over two years ago 
Table 2: List of variables selected from the finisher pig farm survey, Great Britain 2002-03, with univariate odds ratios for the occurrence of fluoroquinolone (FQ) resistant E.coli

\begin{tabular}{|c|c|c|c|c|c|c|c|c|}
\hline \multicolumn{2}{|c|}{ block / Potential Risk Factor } & & \multirow{2}{*}{$\begin{array}{l}\begin{array}{l}\text { farms } \\
\text { with } \\
\text { factor } \\
\text { present }\end{array} \\
51 \%\end{array}$} & \multicolumn{2}{|c|}{$\begin{array}{l}\mathrm{n} \\
\text { exposed }\end{array}$} & \multicolumn{2}{|c|}{$\begin{array}{l}\mathrm{n} \text { not } \\
\text { exposed }\end{array}$} & \multirow[t]{2}{*}{$\begin{array}{l}\text { Odds Ratio } \\
\text { estimate } \\
\left(95 \% \text { C.I. }{ }^{\dagger}\right) \\
20(07-54)\end{array}$} \\
\hline B & DLWG $<695 \mathrm{~g} / \mathrm{d}$ & & & 20 & 13 & 14 & 18 & \\
\hline B & more than 2,000 non breeding pigs on site & 95 & $52 \%$ & 29 & 20 & 23 & 23 & $1.4(0.6-3.3)$ \\
\hline B & pigs kept on single site & 98 & $73 \%$ & 40 & 32 & 14 & 12 & $1.1(0.4-2.7)$ \\
\hline B & post weaning mortality $>=7 \%$ & 67 & $51 \%$ & 23 & 11 & 14 & 19 & $2.8(1.0-7.8)$ \\
\hline B & the farm has sows & 95 & $55 \%$ & 25 & 27 & 27 & 16 & $0.6(0.2-1.3)$ \\
\hline $\mathrm{C}$ & there is a public footpath across site & 100 & $11 \%$ & 5 & 6 & 51 & 38 & $0.6(0.2-2.3)$ \\
\hline $\mathrm{C}$ & one entry/exit for vehicles & 99 & $52 \%$ & 29 & 22 & 27 & 21 & $1.0(0.5-2.3)$ \\
\hline $\mathrm{C}$ & site enclosed by a perimeter fence & 100 & $27 \%$ & 14 & 13 & 42 & 31 & $0.8(0.3-2.0)$ \\
\hline $\mathrm{C}$ & pigs loaded and unloaded at perimeter & 95 & $58 \%$ & 27 & 28 & 25 & 15 & $0.6(0.2-1.3)$ \\
\hline $\mathrm{C}$ & wheel-dip or spray at entrance & 100 & $33 \%$ & 16 & 17 & 40 & 27 & $0.6(0.3-1.5)$ \\
\hline $\mathrm{D}$ & pig farm within 1 mile & 100 & $37 \%$ & 25 & 12 & 31 & 32 & $2.1(0.9-5.1)$ \\
\hline $\mathrm{D}$ & poultry farm within 1 mile & 100 & $29 \%$ & 13 & 16 & 43 & 28 & $0.5(0.2-1.3)$ \\
\hline $\mathrm{D}$ & cattle or sheep farm within 1 mile & 98 & $64 \%$ & 33 & 30 & 22 & 13 & $0.7(0.3-1.5)$ \\
\hline $\mathrm{D}$ & sewage plant within 1 mile & 98 & $11 \%$ & 4 & 7 & 51 & 36 & $0.4(0.1-1.5)$ \\
\hline $\mathrm{D}$ & pig farm upstream on a watercourse within 1 mile & 80 & $21 \%$ & 10 & 7 & 36 & 27 & $1.1(0.4-3.3)$ \\
\hline $\mathrm{D}$ & poultry farm upstream on watercourse within 1 mile & 75 & $15 \%$ & 4 & 7 & 36 & 28 & $0.4(0.1-1.7)$ \\
\hline $\mathrm{D}$ & watercourse across site & 89 & $28 \%$ & 15 & 10 & 34 & 30 & $1.3(0.5-3.5)$ \\
\hline $\mathrm{E}$ & boot-dips emptied weekly & 100 & $52 \%$ & 33 & 19 & 23 & 25 & $1.9(0.8-4.2)$ \\
\hline $\mathrm{E}$ & boot brush provided outside buildings & 99 & $41 \%$ & 28 & 13 & 27 & 31 & $2.5(1.1-5.8)$ \\
\hline $\mathrm{E}$ & boot-dips or sprays provided outside buildings & 100 & $88 \%$ & 52 & 36 & 4 & 8 & $2.9(0.8-11.6)$ \\
\hline $\mathrm{E}$ & detergent used with pressure wash & 98 & $59 \%$ & 34 & 24 & 22 & 18 & $1.2(0.5-2.6)$ \\
\hline $\mathrm{E}$ & visitors free from pig contact for at least 2 days & 100 & $44 \%$ & 19 & 25 & 37 & 19 & $0.4(0.2-0.9)$ \\
\hline $\mathrm{E}$ & hot pressure wash used & 99 & $40 \%$ & 19 & 21 & 37 & 22 & $0.5(0.2-1.2)$ \\
\hline $\mathrm{E}$ & paper towels provided for staff & 100 & $44 \%$ & 22 & 22 & 34 & 22 & $0.7(0.3-1.5)$ \\
\hline $\mathrm{E}$ & hand sanitiser provided for staff & 100 & $49 \%$ & 27 & 22 & 29 & 22 & $0.9(0.4-2.1)$ \\
\hline $\mathrm{E}$ & shower provided for staff & 100 & $25 \%$ & 14 & 11 & 42 & 33 & $1.0(0.4-2.6)$ \\
\hline $\mathrm{E}$ & toilet provided for staff & 100 & $68 \%$ & 38 & 30 & 18 & 14 & $1.0(0.4-2.3)$ \\
\hline $\mathrm{E}$ & overalls and boots used staff & 97 & $75 \%$ & 40 & 33 & 14 & 10 & $0.9(0.3-2.2)$ \\
\hline $\mathrm{E}$ & overalls and boots used visitor & 99 & $70 \%$ & 38 & 31 & 18 & 12 & $0.8(0.3-2.0)$ \\
\hline $\mathrm{F}$ & received gilts & 99 & $28 \%$ & 16 & 12 & 40 & 31 & $1.0(0.4-2.6)$ \\
\hline $\mathrm{F}$ & received growers & 100 & $28 \%$ & 19 & 9 & 37 & 35 & $2.0(0.8-5.2)$ \\
\hline $\mathrm{F}$ & received weaners & 100 & $22 \%$ & 12 & 10 & 44 & 34 & $0.9(0.4-2.5)$ \\
\hline $\mathrm{F}$ & received weaners or growers & 100 & $47 \%$ & 30 & 17 & 26 & 27 & $1.8(0.8-4.1)$ \\
\hline G & wild birds have access to any & 93 & $75 \%$ & 40 & 30 & 13 & 10 & $1.0(0.4-2.7)$ \\
\hline G & own rodent control (not contractor) & 97 & $80 \%$ & 44 & 34 & 10 & 9 & $1.2(0.4-3.2)$ \\
\hline G & rat or mice situation is minor or major problem & 99 & $47 \%$ & 23 & 24 & 32 & 20 & $0.6(0.3-1.3)$ \\
\hline G & wild birds seen in moderate or high numbers & 97 & $40 \%$ & 24 & 15 & 30 & 28 & $1.5(0.7-3.5)$ \\
\hline $\mathrm{H}$ & cattle or sheep on site now or in $12 \mathrm{mths}$ & 99 & $29 \%$ & 15 & 14 & 40 & 30 & $0.8(0.3-1.9)$ \\
\hline $\mathrm{H}$ & dogs or cats have access to any building & 97 & $71 \%$ & 39 & 30 & 15 & 13 & $1.1(0.5-2.8)$ \\
\hline $\mathrm{H}$ & dog or cat on site now or in $12 \mathrm{mths}$ & 99 & $87 \%$ & 48 & 38 & 7 & 6 & $1.1(0.3-3.6)$ \\
\hline $\mathrm{H}$ & horses on site now or in $12 \mathrm{mths}$ & 99 & $24 \%$ & 14 & 10 & 41 & 34 & $1.2(0.5-3.0)$ \\
\hline $\mathrm{H}$ & poultry on site now or in $12 \mathrm{mths}$ & 99 & $17 \%$ & 12 & 5 & 43 & 39 & $2.2(0.7-7.4)$ \\
\hline
\end{tabular}


Table 2, continued...

\begin{tabular}{|c|c|c|c|c|c|c|c|}
\hline block / Potential Risk Factor & \multirow{2}{*}{$\frac{\mathrm{n}}{100}$} & $\begin{array}{l}\% \\
\text { farms } \\
\text { with } \\
\text { factor } \\
\text { present }\end{array}$ & \multicolumn{2}{|c|}{$\begin{array}{l}\mathrm{n} \\
\text { exposed }\end{array}$} & \multicolumn{2}{|c|}{$\begin{array}{l}\text { n not } \\
\text { exposed }\end{array}$} & \multirow{2}{*}{$\begin{array}{l}\text { Odds Ratio } \\
\text { estimate } \\
\frac{\left(95 \% \text { C.I. }^{\dagger}\right)}{2.7(0.8-10.4)}\end{array}$} \\
\hline bagged feed kept in pig buildings or accommodation & & $16 \%$ & 12 & 4 & 44 & 40 & \\
\hline bulk bins cleaned every batch & 89 & $22 \%$ & 13 & 7 & 37 & 32 & $1.6(0.6-4.7)$ \\
\hline feed stored uncovered on trailer or floor or bin & 100 & $16 \%$ & 7 & 9 & 49 & 35 & $0.6(0.2-1.7)$ \\
\hline top housekeeping score & 107 & $18 \%$ & 11 & 8 & 52 & 36 & $1.0(0.3-2.7)$ \\
\hline L FQ used during last $12 \mathrm{mth}$ & 108 & $49 \%$ & 44 & 9 & 19 & 36 & $9.3(3.7-23.5)$ \\
\hline FQ used anytime in recent past & 108 & $66 \%$ & 56 & 15 & 7 & 30 & $16.0(5.9-44.9)$ \\
\hline M aminoglycoside+penicillin supplied in last 12 months & 108 & $42 \%$ & 22 & 23 & 41 & 22 & $0.5(0.2-1.1)$ \\
\hline $\begin{array}{l}\text { M aminoglycoside supplied in last } 12 \text { months } \\
\text { non-steroidal anti-inflammatory drug supplied in last }\end{array}$ & 108 & $40 \%$ & 28 & 15 & 35 & 30 & $1.6(0.7-3.6)$ \\
\hline M 12 months & 108 & $17 \%$ & 9 & 9 & 54 & 36 & $0.7(0.2-1.9)$ \\
\hline M broad spectrum penicillin supplied in last 12 months & 108 & $62 \%$ & 42 & 25 & 21 & 20 & $1.6(0.7-3.5)$ \\
\hline M cephalosporin supplied in last 12 months & 108 & $25 \%$ & 23 & 4 & 40 & 41 & $5.9(1.9-21.2)$ \\
\hline M macrolide supplied in last 12 months & 108 & $96 \%$ & 59 & 45 & 4 & 0 & -- \\
\hline M penicillin supplied in last 12 months & 108 & $72 \%$ & 54 & 24 & 9 & 21 & $5.2(2.1-13.5)$ \\
\hline M penicillin+sulphadimidine supplied in last 12 months & 108 & $4 \%$ & 1 & 3 & 62 & 42 & $0.2(0.0-2.2)$ \\
\hline M pleuromutilin supplied in last 12 months & 108 & $19 \%$ & 11 & 9 & 52 & 36 & $0.8(0.3-2.3)$ \\
\hline $\begin{array}{l}\text { M potentiated sulphonamide supplied in last } 12 \text { months } \\
\text { steroidal anti-inflammatory drug supplied in last } 12\end{array}$ & 108 & $56 \%$ & 38 & 22 & 25 & 23 & $1.6(0.7-3.5)$ \\
\hline M months & 108 & $26 \%$ & 20 & 8 & 43 & 37 & $2.1(0.9-5.7)$ \\
\hline M tranquiliser ('stresnil') supplied in last 12 months & 108 & $36 \%$ & 19 & 20 & 44 & 25 & $0.5(0.2-1.2)$ \\
\hline M tetracycline supplied in last 12 months & 108 & $89 \%$ & 54 & 42 & 9 & 3 & $0.4(0.1-1.6)$ \\
\hline season: spring compared with autumn/winter & 81 & $68 \%$ & 30 & 25 & 9 & 17 & $2.3(0.9-6.1)$ \\
\hline season: summer compared with autumn/winter & 53 & $51 \%$ & 24 & 3 & 9 & 17 & $15.1(3.6-73.5)$ \\
\hline
\end{tabular}

\section{Table notes:}

$\mathrm{R}+$ : $\quad$ number of farms positive for FQ-resistant E.coli

R- : $\quad$ number of farms negative for FQ-resistant E.coli

$\dagger: \quad$ confidence intervals based on mid-p inference using exact conditional logistic regression.

Shaded rows indicate the variables included in the final multivariate model (see Table 4)

\section{Key to variable blocks:}

block B: general characteristics of farm

block C: perimeter security

block D: possible sources of bacteria around the farm

block E: farm biosecurity and hygiene

block F: pigs moved onto the farm

block G: vermin around the site

block H: other animals around the site

block I: handling of pig feed

block J: housekeeping score judged by the vet filling in the questionnaire (this factor contains a 'bundle' of detail related to maintenance, cleaning and biosecurity on the farm)

block L: recent use of FQ

block M: use of drugs, other than fluoroquinolone antibiotics, in the last 12 months 
Table 3: List of variables selected from the finisher pig farm survey, Great Britain 2002-03, with univariate odds ratios for the occurrence of fluoroquinolone (FQ) resistant Campylobacter

\begin{tabular}{|c|c|c|c|c|c|c|c|c|}
\hline & & & $\begin{array}{l}\% \\
\text { farms } \\
\text { with } \\
\text { factor }\end{array}$ & & & & & $\begin{array}{l}\text { Odds Ratio } \\
\text { estimate }\end{array}$ \\
\hline & ck / Potential Risk Factor & $\mathrm{n}$ & present & $\mathrm{R}+$ & R- & $\mathrm{R}+$ & $\mathrm{R}-$ & $\left(95 \%\right.$ C.I. $\left.{ }^{\dagger}\right)$ \\
\hline B & DLWG $<695 \mathrm{~g} / \mathrm{d}$ & 65 & $51 \%$ & 22 & 11 & 23 & 9 & $0.8(0.3-2.3)$ \\
\hline B & more than 2,000 non breeding pigs on site & 95 & $52 \%$ & 37 & 12 & 33 & 13 & $1.2(0.5-3.1)$ \\
\hline B & pigs kept on single site & 98 & $73 \%$ & 55 & 17 & 18 & 8 & $1.4(0.5-3.9)$ \\
\hline B & post weaning mortality $>=7 \%$ & 67 & $51 \%$ & 27 & 7 & 20 & 13 & $2.5(0.8-7.7)$ \\
\hline $\mathrm{B}$ & the farm has sows & 95 & $55 \%$ & 33 & 19 & 37 & 6 & $0.3(0.1-0.8)$ \\
\hline $\mathrm{C}$ & there is a public footpath across site & 100 & $11 \%$ & 8 & 3 & 67 & 22 & $0.9(0.2-4.4)$ \\
\hline $\mathrm{C}$ & one entry/exit for vehicles & 99 & $52 \%$ & 41 & 10 & 33 & 15 & $1.9(0.7-4.8)$ \\
\hline $\mathrm{C}$ & site enclosed by a perimeter fence & 100 & $27 \%$ & 18 & 9 & 57 & 16 & $0.6(0.2-1.5)$ \\
\hline $\mathrm{C}$ & pigs loaded and unloaded at perimeter & 95 & $58 \%$ & 37 & 18 & 33 & 7 & $0.4(0.2-1.2)$ \\
\hline $\mathrm{C}$ & wheel-dip or spray at entrance & 100 & $33 \%$ & 24 & 9 & 51 & 16 & $0.8(0.3-2.2)$ \\
\hline $\mathrm{D}$ & pig farm within 1 mile & 100 & $37 \%$ & 31 & 6 & 44 & 19 & $2.2(0.8-6.7)$ \\
\hline $\mathrm{D}$ & poultry farm within 1 mile & 100 & $29 \%$ & 24 & 5 & 51 & 20 & $1.9(0.6-6.2)$ \\
\hline $\mathrm{D}$ & cattle or sheep farm within 1 mile & 98 & $64 \%$ & 47 & 16 & 26 & 9 & $1.0(0.4-2.6)$ \\
\hline $\mathrm{D}$ & sewage plant within 1 mile & 98 & $11 \%$ & 9 & 2 & 64 & 23 & $1.6(0.4-11.6)$ \\
\hline $\mathrm{D}$ & pig farm upstream on a watercourse within 1 mile & 80 & $21 \%$ & 16 & 1 & 47 & 16 & $5.4(0.9-122.1)$ \\
\hline $\mathrm{D}$ & poultry farm upstream on watercourse within 1 mile & 75 & $15 \%$ & 10 & 1 & 48 & 16 & $3.3(0.5-77.3)$ \\
\hline $\mathrm{D}$ & watercourse across site & 89 & $28 \%$ & 18 & 7 & 50 & 14 & $0.7(0.3-2.2)$ \\
\hline E & boot-dips emptied weekly & 100 & $52 \%$ & 42 & 10 & 33 & 15 & $1.9(0.8-4.9)$ \\
\hline $\mathrm{E}$ & boot brush provided outside buildings & 99 & $41 \%$ & 37 & 4 & 37 & 21 & $5.2(1.7-19.1)$ \\
\hline $\mathrm{E}$ & boot-dips or sprays provid & 100 & $88 \%$ & 69 & 19 & 6 & 6 & $3.6(1.0-13.0)$ \\
\hline $\mathrm{E}$ & detergent used with pressure wash & 98 & $59 \%$ & 43 & 15 & 31 & 9 & $0.8(0.3-2.2)$ \\
\hline $\mathrm{E}$ & visitors free from pig contact for at least 2 days & 100 & $44 \%$ & 26 & 18 & 49 & 7 & $0.2(0.1-0.6)$ \\
\hline $\mathrm{E}$ & hot pressure wash used & 99 & $40 \%$ & 25 & 15 & 50 & 9 & $0.3(0.1-0.8)$ \\
\hline $\mathrm{E}$ & paper towels provided for staff & 100 & $44 \%$ & 31 & 13 & 44 & 12 & $0.7(0.3-1.6)$ \\
\hline $\mathrm{E}$ & hand sanitiser provided for staff & 100 & $49 \%$ & 34 & 15 & 41 & 10 & $0.6(0.2-1.4)$ \\
\hline $\mathrm{E}$ & shower provided for staff & 100 & $25 \%$ & 16 & 9 & 59 & 16 & $0.5(0.2-1.3)$ \\
\hline $\mathrm{E}$ & toilet provided for staff & 100 & $68 \%$ & 49 & 19 & 26 & 6 & $0.6(0.2-1.7)$ \\
\hline $\mathrm{E}$ & overalls and boots used staff & 97 & $75 \%$ & 56 & 17 & 17 & 7 & $1.4(0.5-3.8)$ \\
\hline E & overalls and boots used visitor & 99 & $70 \%$ & 48 & 21 & 26 & 4 & $0.4(0.1-1.1)$ \\
\hline $\mathrm{F}$ & received gilts & 99 & $28 \%$ & 22 & 6 & 52 & 19 & $1.3(0.5-4.1)$ \\
\hline $\mathrm{F}$ & received growers & 100 & $28 \%$ & 26 & 2 & 49 & 23 & $6.1(1.5-40.5)$ \\
\hline $\mathrm{F}$ & received weaners & 100 & $22 \%$ & 18 & 4 & 57 & 21 & $1.7(0.5-6.3)$ \\
\hline $\mathrm{F}$ & received weaners or growers & 100 & $47 \%$ & 41 & 6 & 34 & 19 & $3.8(1.4-11.4)$ \\
\hline G & wild birds have access to any building & 93 & $75 \%$ & 54 & 16 & 15 & 8 & $1.8(0.6-5.0)$ \\
\hline G & own rodent control (not contractor) & 97 & $80 \%$ & 59 & 19 & 14 & 5 & $1.1(0.3-3.4)$ \\
\hline G & rat or mice situation is minor or major problem & 99 & $47 \%$ & 32 & 15 & 42 & 10 & $0.5(0.2-1.3)$ \\
\hline G & wild birds seen in moderate or high numbers & 97 & $40 \%$ & 31 & 8 & 41 & 17 & $1.6(0.6-4.4)$ \\
\hline $\mathrm{H}$ & cattle or sheep on site now or in $12 \mathrm{mths}$ & 99 & $29 \%$ & 21 & 8 & 53 & 17 & $0.8(0.3-2.4)$ \\
\hline $\mathrm{H}$ & dogs or cats have access to any building & 97 & $71 \%$ & 55 & 14 & 17 & 11 & $2.5(0.9-6.7)$ \\
\hline $\mathrm{H}$ & dog or cat on site now or in $12 \mathrm{mths}$ & 99 & $87 \%$ & 67 & 19 & 7 & 6 & $3.0(0.8-10.3)$ \\
\hline $\mathrm{H}$ & horses on site now or in $12 \mathrm{mths}$ & 99 & $24 \%$ & 18 & 6 & 56 & 19 & $1.0(0.4-3.2)$ \\
\hline $\mathrm{H}$ & poultry on site now or in $12 \mathrm{mths}$ & 99 & $17 \%$ & 13 & 4 & 61 & 21 & $1.1(0.3-4.4)$ \\
\hline
\end{tabular}


Table 3, continued...

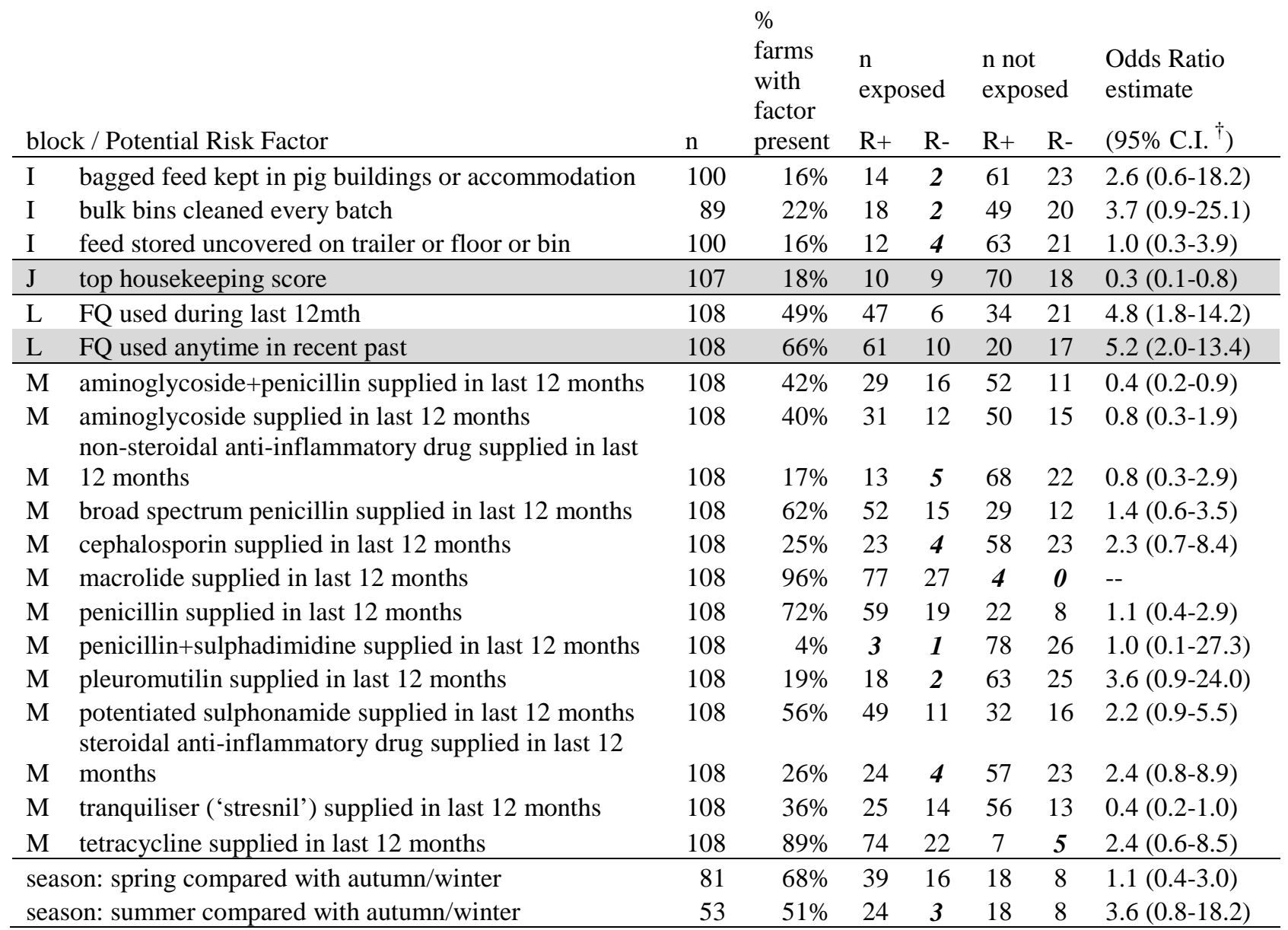

\section{Table notes:}

$\mathrm{R}+$ : $\quad$ number of farms positive for FQ-resistant Campylobacter

R- : $\quad$ number of farms negative for FQ-resistant Campylobacter

$\dagger: \quad$ confidence intervals based on mid-p inference using exact conditional logistic regression.

Shaded rows indicate the variables included in the final multivariate model (see Table 5)

\section{Key to variable blocks:}

block B: general characteristics of farm

block C: perimeter security

block D: possible sources of bacteria around the farm

block E: farm biosecurity and hygiene

block F: pigs moved onto the farm

block G: vermin around the site

block H: other animals around the site

block I: handling of pig feed

block J: housekeeping score judged by the vet filling in the questionnaire (this factor contains a 'bundle' of detail related to maintenance, cleaning and biosecurity on the farm)

block L: recent use of FQ

block M: use of drugs, other than fluoroquinolone antibiotics, in the last 12 months 
Table 4: Estimated adjusted odds ratios of variables included as risk factors in the final multiple logistic regression model for the detection of fluoroquinolone (FQ)-resistant $E$. coli on finisher pig farms in Great Britain during 2002-03

\begin{tabular}{|c|c|c|c|c|c|}
\hline Risk factor & $\begin{array}{l}\text { Co- } \\
\text { efficient }\end{array}$ & p-value* & $\begin{array}{r}\text { Lower limit } \\
95 \% \text { C.I. }{ }^{\dagger}\end{array}$ & $\begin{array}{c}\text { Odds ratio } \\
\text { point estimate }\end{array}$ & $\begin{array}{l}\text { Upper limit } \\
\text { 95\%C.I. }{ }^{\dagger}\end{array}$ \\
\hline Constant & -2.117 & & & & \\
\hline $\begin{array}{l}\text { Use of FQ at any time in } \\
\text { recent past }\end{array}$ & 2.802 & $<0.0001$ & 4.44 & 16.50 & 44.80 \\
\hline $\begin{array}{l}\text { There is another pig farm } \\
\text { within } 1 \text { mile }\end{array}$ & 1.238 & 0.0761 & 0.81 & 3.45 & 14.75 \\
\hline $\begin{array}{l}\text { There is a poultry farm } \\
\text { within } 1 \text { mile }\end{array}$ & -1.230 & 0.0769 & 0.07 & 0.29 & 1.24 \\
\hline $\begin{array}{l}\text { Visitors are required to } \\
\text { be free of pig contact for } \\
\text { at least two days }\end{array}$ & -0.915 & 0.0977 & 0.14 & 0.40 & 1.25 \\
\hline Season & & 0.0078 & & & \\
\hline Spring vs autumn/winter & 0.936 & 0.15 & 0.69 & 2.55 & 8.82 \\
\hline $\begin{array}{l}\text { Summer vs } \\
\text { autumn/winter }\end{array}$ & 2.541 & 0.0045 & 1.94 & 12.69 & 67.03 \\
\hline
\end{tabular}

$\mathrm{n}=100$

Maximum re-scaled $\mathrm{r}^{2}=56.0 \%$

* p-value is based on likelihood ratio test, apart from specific comparisons involving season which are based on the Wald test.

$\dagger$ exact (mid-p) confidence intervals 
Table 5: Estimated adjusted odds ratios of variables included as risk factors in the final multiple logistic regression model for the detection of fluoroquinolone (FQ)-resistant Campylobacter spp. on finisher pig farms in Great Britain during 2002-03

\begin{tabular}{|c|c|c|c|c|c|}
\hline Risk factor & $\begin{array}{l}\text { Co- } \\
\text { efficient }\end{array}$ & p-value* & $\begin{array}{l}\text { Lower limit } \\
95 \% \text { C.I. }\end{array}$ & $\begin{array}{c}\text { Odds ratio } \\
\text { point estimate }\end{array}$ & $\begin{array}{l}\text { Upper limit } 95 \% \\
\text { C.I. }^{\dagger}\end{array}$ \\
\hline Constant & 0.066 & & & & \\
\hline $\begin{array}{l}\text { Use of FQ at any time in } \\
\text { recent past }\end{array}$ & 2.111 & 0.0003 & 2.26 & 8.26 & 26.45 \\
\hline $\begin{array}{l}\text { Brought in growers } \\
\text { within past year }\end{array}$ & 1.456 & 0.062 & 0.82 & 4.29 & 28.94 \\
\hline $\begin{array}{l}\text { Visitors required to be } \\
\text { free of pig contact for at } \\
\text { least two days }\end{array}$ & -1.106 & 0.069 & 0.10 & 0.33 & 1.16 \\
\hline $\begin{array}{l}\text { Boot brush provided with } \\
\text { boot dips }\end{array}$ & 1.549 & 0.020 & 1.14 & 4.71 & 19.40 \\
\hline $\begin{array}{l}\text { Farm given the top } \\
\text { housekeeping score }\end{array}$ & -1.389 & 0.066 & 0.06 & 0.25 & 1.22 \\
\hline
\end{tabular}

$\mathrm{n}=98$

Maximum re-scaled $\mathrm{r}^{2}=46.5 \%$

* p-value is based on likelihood ratio test.

$\dagger$ exact (mid-p) confidence intervals 


\section{REFERENCES}

1. Swann M. Report of the joint committee on the use of antibiotics in animal husbandry and veterinary medicine (Cmnd 4190). London: HMSO; 1969.

2. Endtz HP, et al. Quinolone resistance in Campylobacter isolated from man and poultry following the introduction of fluoroquinolones in veterinary medicine. Journal of Antimicrobial Chemotherapy 1991; 27: 199-208.

3. Threlfall EJ, et al. Increase in multiple antibiotic resistance in nontyphoidal salmonellas from humans in England and Wales: a comparison of data for 1994 and 1996. Microbial Drug Resistance 1997; 3: 263-266.

4. Harvey RB, et al. Prevalence of Campylobacter spp. isolated from the intestinal tract of pigs raised in an integrated swine production system. Journal of the American Veterinary Medical Association 1999; 215: 1601-1604.

5. Milnes A, et al. Intestinal carriage of verocytotoxigenic Escherichia coli O157, Salmonella, thermophilic Campylobacter and Yersinia enterocolitica, in cattle, sheep and pigs at slaughter in Great Britain during 2003. Epidemiology and Infection 2008; 136: 739-751.

6. Pezzotti G, et al. Occurrence and resistance to antibiotics of Campylobacter jejuni and Campylobacter coli in animals and meat in northeastern Italy. International Journal of Food Microbiology 2003; 82: 281-287.

7. Taylor DJ. Pig Diseases, 4th edn. Glasgow: D. J. Taylor, 1986, pp. 330.

8. Payot S, et al. Prevalence and antimicrobial resistance of Campylobacter coli isolated from fattening pigs in France. Veterinary Microbiology 2004; 101: 91-99.

9. Schuppers ME, et al. Clinical herd health, farm management and antimicrobial resistance in Campylobacter coli on finishing pig farms in Switzerland. Preventive Veterinary Medicine 2005; 69: 189-202.

10. Thakur S, Gebreyes WA. Prevalence and antimicrobial resistance of Campylobacter in antimicrobial-free and conventional pig production systems. Journal of Food Protection 2005; 68: $2402-2410$.

11. Young CR, et al. Enteric colonisation following natural exposure to Campylobacter in pigs. Research in Veterinary Science 2000; 68: 75-78.

12. Guevremont E, Higgins R, Quessy S. Characterization of Campylobacter isolates recovered from clinically healthy pigs and from sporadic cases of campylobacteriosis in humans. Journal of Food Protection 2004; 67: 228-234.

13. Litrup E, Torpdahl M, Nielsen EM. Multilocus sequence typing performed on Campylobacter coli isolates from humans, broilers, pigs and cattle originating in Denmark. Journal of Applied Microbiology 2007; 103: 210-218.

14. Siemer BL, Nielsen EM, On SL. Identification and molecular epidemiology of Campylobacter coli isolates from human gastroenteritis, food, and animal sources by amplified fragment length polymorphism analysis and Penner serotyping. Applied and Environmental Microbiology 2005; 71: 1953-1958. 
15. Delsol AA, et al. Emergence of fluoroquinolone resistance in the native Campylobacter coli population of pigs exposed to enrofloxacin. Journal of Antimicrobial Chemotherapy 2004; 53: 872-874.

16. Engberg J, et al. Quinolone and macrolide resistance in Campylobacter jejuni and C. coli: resistance mechanisms and trends in human isolates. Emerging Infectious Diseases 2001; 7: 24-34.

17. Gupta A, et al. Antimicrobial resistance among Campylobacter strains, United States, 19972001. Emerging Infectious Diseases 2004; 10: 1102-1109.

18. Moore JE, et al. The epidemiology of antibiotic resistance in Campylobacter. Microbes and Infection 2006; 8: 1955-1966.

19. Hartl DL, Dykhuizen DE. The population genetics of Escherichia coli. Annual Review of Genetics 1984; 18: 31-68.

20. Threlfall EJ, et al. Antibiotic resistance in Escherichia coli isolated from blood and cerebrospinal fluid: a 6-year study of isolates from patients in England and Wales. International Journal of Antimicrobial Agents 1998; 9: 201-205.

21. Webber M, Piddock LJ. Quinolone resistance in Escherichia coli. Veterinary Research 2001; 32: $275-284$.

22. Aarestrup FM, Wegener HC. The effects of antibiotic usage in food animals on the development of antimicrobial resistance of importance for humans in Campylobacter and Escherichia coli. Microbes and Infection 1999; 1: 639-644.

23. Taylor NM, et al. A survey of fluoroquinolone resistance in E. coli and thermophilic Campylobacter spp. on poultry and pig farms in Great Britain. Journal of Applied Microbiology; In in press. Published online: 5 Sept 2008; doi: 10.1111/j.13652672.2008.03877.x

24. Shreeve JE, et al. The carry-over of Campylobacter isolates between sequential poultry flocks. Avian Diseases 2002; 46: 378-385.

25. NCCLS (National Committee for Clinical Laboratory Standards). Methods for dilution antimicrobial susceptibility tests for bacteria that grow aerobically - fourth edition; Approved standard. NCCLS document M7-A4 (ISBN 1-56238-309-4). Wayne, Pennsylvania, USA: NCCLS, 1997.

26. Randall LP, et al. Prevalence of multiple antibiotic resistance in 443 Campylobacter spp. isolated from humans and animals. Journal of Antimicrobial Chemotherapy 2003; 52: 507-510.

27. SAS Institute Inc. SAS ${ }^{\circledR}$ statistical software version 8.2. Cary, North Carolina, USA, 2001.

28. Agresti A. An introduction to categorical data analysis, 2nd edition. Hoboken, New Jersey, USA: John Wiley and Sons, Inc., 2007, pp. 372.

29. Sprent P, Smeaton NC. Applied nonparametric statistical methods, 3rd edn. Chapman \& Hall/CRC Texts in Statistical Science. London: Chapman and Hall/CRC, 2001, pp. 461.

30. Everitt BS. Cluster analysis, 2nd edn. London: Heinemann Educational Books Ltd., 1980, pp. 136.

31. Ward JH. Hierarchical grouping to optimise an objective function. Journal of the American Statistical Association 1963; 58: 236-244.

32. Collett D. Modelling binary data, 2nd edn. Texts in statistical science. London: Chapman \& Hall/CRC, 2003, pp. 408. 
33. Nagelkerke NJD. A note on a general definition of the coefficient of determination. Biometrika 1991; 78: 691-692.

34. Sander $\mathbf{P}$, et al. Fitness cost of chromosomal drug resistance-conferring mutations. Antimicrobial Agents and Chemotherapy 2002; 46: 1204-1211.

35. Schrag SJ, Perrot V, Levin BR. Adaptation to the fitness cost of antibiotic resistance in Escherichia coli. Proceedings of the Royal Society B: Biological Sciences 1997; 264: 12871291.

36. Zhang Q, Lin J, Pereira S. Fluoroquinolone-resistant Campylobacter in animal reservoirs: dynamics of development, resistance mechanisms and ecological fitness. Animal Health Research Reviews 2003; 4: 63-71.

37. LeJeune JT, Besser TE, Hancock DD. Cattle water troughs as reservoirs of Escherichia coli O157. Applied and Environmental Microbiology 2001; 67: 3053-3057.

38. Sjogren RE. 13-year survival study of an environmental Escherichia coli in field mini-plots. Water Air and Soil Pollution 1995; 81: 315-335.

39. Keller J, Perreten V. Genetic diversity in fluoroquinolone and macrolide-resistant Campylobacter coli from pigs. Veterinary Microbiology 2006; 113: 103-108.

40. Weijtens MJ, et al. Campylobacter infections in fattening pigs; excretion pattern and genetic diversity. Journal of Applied Microbiology 1999; 86: 63-70.

41. Weijtens MJ, et al. Prevalence of Campylobacter in pigs during fattening; an epidemiological study. Veterinary Quarterly 1993; 15: 138-143.

42. Weijtens MJ, et al. The transmission of Campylobacter in piggeries; an epidemiological study. Journal of Applied Microbiology 1997; 83: 693-698.

43. Dunlop RH, et al. Associations among antimicrobial drug treatments and antimicrobial resistance of fecal Escherichia coli of swine on 34 farrow-to-finish farms in Ontario, Canada. Preventive Veterinary Medicine 1998; 34: 283-305.

44. Bayer Healthcare. Guidelines for the use of quinolones in veterinary medicine: prudent therapeutic use of quinolones in food-producing animals. (http://www.poultry.baytril.com/165/Downloads.htm) Accessed October 72008. 